\title{
Sistem Informasi Inventaris Berbasis Android Berbasis Android Pada SMP IT NURUL MUHAJIRIN
}

\author{
Ririt Dwiputri Permatasari ${ }^{1}$, Alexsandri Sikumbang ${ }^{2}$, Almurdani ${ }^{3}$ \\ ${ }^{1,2}$ Universitas Ibnu Sina; Jalan Teuku Umar - Lubuk Baja, Batam, Kepulauan Riau \\ ${ }^{3}$ Program Studi Teknik Informatika, Universitas Ibnu Sina, Batam \\ e-mail: *, ririt@ uis.ac.id, ${ }^{1}$ alexsandri@uis.ac.id, ${ }^{3} 1610128262196 @$ uis.ac.id
}

\begin{abstract}
Abstrak
Bidang sarana prasarana merupakan bidang yang mengelola setiap data inventaris barang pada SMPS IT NURUL MUHAJIRIN. Data-data yang telah dikelola pun akan disimpan pada catatan buku besar, data-data yang tersimpan di catatan buku bsar nantinya akan dicatatan ulang bila terjadi kerusakan pada catatan buku besar tersebut. Setelah mengetahui dasar pada penyimpanan data di catatan buku besar tidak lah memberikan jangka waktu yang lama pada data-data inventaris barang. Maka dari ini penulis melatarbelakangi untuk membuat sistem yang akan bisa digunakan pada bidang sarana prasarana untuk mendata segala inventaris barang di SMP IT NURUL MUHAJIRIN. Sistem tersebut berupa aplikasi berrbasis android dengan menggunakan metode waterfall untuk merancang dan membangun sistem aplikasi inventaris barang. Tahapan-tahapan pada metode waterfall yang akan memeberikan papapan dalam merancang dan membangun sistem inventaris berbasis aplikasi android. Sistem inventaris berbasis aplikasi android akan melakukan percoabaan pada bidang sarana prasrana di SMP IT NURUL MUHAJIRIN. Setelah selsai pada percoabaan yang dilakukan, nanti nya akan bisa dipergunakan pada bidang sarana prasarana untuk melakukan pekerjaan mendata semua mengenai inventaris barang di SMP IT NURUL MUHAJIRIN.
\end{abstract}

Kata kunci- Inventaris, Metode waterfall, Sistem aplikasi android

\section{Abstract}

The field of infrastructure is a field that manages every item inventory data at SMPS IT NURUL MUHAJIRIN. The data that has been managed will also be stored in the ledger records, the data stored in the ledger records will later be re-recorded if there is damage to the ledger records. After knowing the basis of storing data in ledger records, it does not provide a long period of time on inventory data. So from this the author is behind to create a system that will be used in the field of infrastructure to record all inventory of goods at SMP IT NURUL MUHAJIRIN. The system is an android-based application using the waterfall method to design and build an inventory application system. The stages in the waterfall method that will provide a board in designing and building an Android application-based inventory system. An Android application-based inventory system will conduct experiments in the field of infrastructure at SMP IT NURUL MUHAJIRIN. After completing the experiment, it will be used in the field of infrastructure to carry out the work of recording all of the inventory of goods at SMP IT NURUL MUHAJIRIN.

Keywords - Inventory, Waterfall method, Android application system 


\section{PENDAHULUAN}

Pada zaman modern saat ini manusia masih sangat membutuhkan teknologi bukan hanya dari dunia pendidikan, perdagangan, maupun bidang-bidang lainnya [1]. Hal ini berpacu dalam meningkatkan sumber daya manusia untuk kinerja guna mengimbangi perkembangan teknologi yang setiap tahun nya mengalami kemajuan. kinerja yang telah dilakukan bidang sarana prasarana untuk memberikan data-data yang cukup akurat agar tidak menajdi kesalahan dalam bekerja di SMP IT NURUL MUHAJIRIN untuk mendata setiap barang-barang yang di input.

Pengolahan memang lah sangat tidak mudah dalam meng input data-data inventaris agar tidak terjadi kesalahan dalam meng input. Data inventaris barang yang di input melalui catatan cuku besar merupakan data yang anantinya akan dibuat laporan sebagai data bulanan dan tahunan kepada bapak kepala SMP IT NURUL MUHAJIRIN[3]. Kesalahan dan kekurangan data-data inventaris barang pada catatan buku besar sering kali terjadi apa bila ingin melakukakan pencatatan ulang slalu data tidak lengkap, data-data pada catatan buku besar juga tidak bisa menjamin data bisa bertahan lama.

Merujuk dari permasalahan tersebut, maka judul penelitian ini adalah "Sistem Informasi Inventaris Berbasis Android Pada SMP IT NURUL MUAJIRIN" yang diharapkan dapat menjadi solusi dan dapat memberikan kelancaran dalam proses meng input data-data inventaris barang di bidang sarana prasarana pada SMP IT NURUL MUHAJIRIN.

\section{METODE PENELITIAN}

Penelitian ini menggunakan tahapan metode waterfall berupa Analisa kebutuhan, perancangan awal, pengkodean dan pengujian, penerapan dan pengujian, dan pemeliharaan [5].

Metode waterfall tersebut merupakan proses yang sangat mudah dipahami dan memberikan tahapan-tahapan yang dijalani oleh sistem.

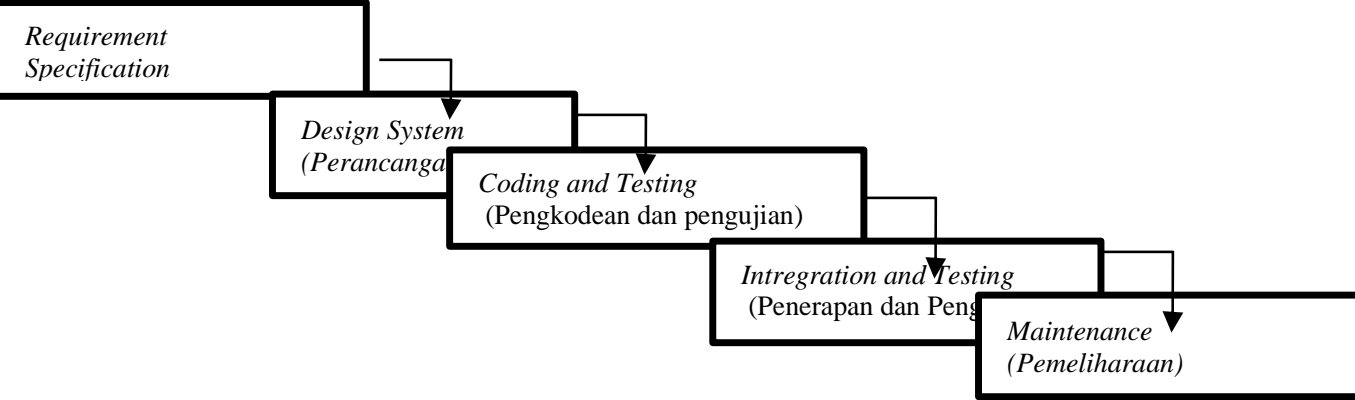

\section{Gambar 1 Tahapan Metode Waterfall}

Tahapan sistem informasi invenaris berbasis android dengan metode waterfall [7] yaitu:

1. Requirement Specification (Analisa Kebutuhan)

Melakukan pengumpulan data primer dan data sekunder pada tempat studi kasus agar mengetahui segala kekurangan dalam membutuhkan pada sistem nantinya.

2. Design System (Desain Sistem)

Tahap ini merupakan dimana setelah mengetaui sistem yang telah digunakan pada bidang sarana prasarana atau Aliran sistem lama. Selanjutnya dimana membuat aliran sistem baru yang akan digunakan nantinya pada sistem inventaris barang.

3. Coding and Testing (Pengkodean dan pengujian)

Merupakan tahap perancangan untuk melakukan pengkodean dalam proses pada sistem yang akan digunakan nantinya. 
4. Integration and Testing (Penerapan dan Peengujia)

Tahap pengujian dimana sistem akan dijalankan agar mengetahui proses pada sistem bisa berjalan sesuai prosedur yang di inginkan agar tidak ada kesalhan ataupun eror pada sistem tersebut.

5. Maintenance (Pemeliharaan)

Tahap terakhir merupakan tahap pemeliharaan yang dilakukan bersekala. Setelah sistem diunakan pada bidang sarana prasarana dan tidak terjadi kendala, memungkinkan sistem akan bisa diperbarui sesuai keinginan dari bidang sarana prasarana.

\section{HASIL DAN PEMBAHASAN}

Pembuatan sistem informasi inventaris berbasis android pada SMP IT NURURL MUHAJIRIN menggunakan implementasi dari tahapan-tahapan metode Waterfall yang terdiri dari 5 (lima) tahapan yaitu Requirement Specification (Analisa Kebutuhan), Design System (Desain Sistem), Coding and Testing (Pengkodean dan Pengujian), Integration and Testing (Penerapan dan Pengujian) dan Maintenance (Pemeliharaan) yang terangkum proses tahapan Waterfall [9].

\subsection{Tahap-tahap proses implementasi Waterfall}

Tahap ini dimana akan dijelaskan proses pengerjaan secara bertahap memalui tahapan metode Waterfall yaitu:

1. Aliran sistem yang digunakan

Sebelum memulai proses tahapan Waterfall, harus terlebih dahulu mengetahui sistem yang sedang digunakan atau sistem yang berjalan pada sistem inventaris baraang dibidang sarana prasrana.

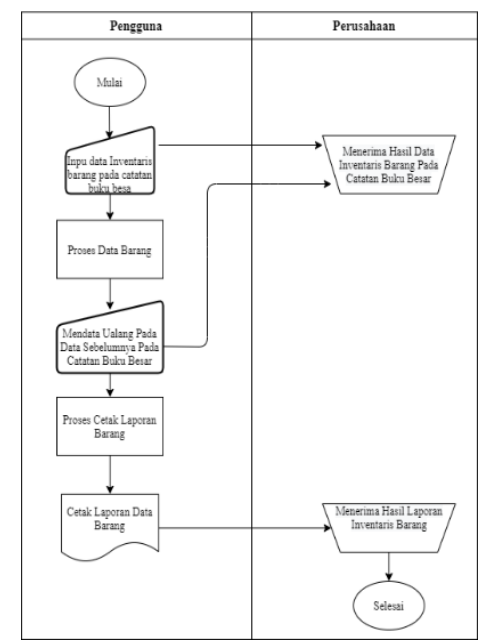

Gambar 2 Sistem sedang berjalan

2. Aliran sistem yang di usulkan

Setelah mengetahui sistem yang sedang digunakan atau berjalan pada sistem inventaris barang dibidang sarana prasarana, selanjutnya merancnga aliran sistem yang akan di usulkan yang mana sistem akan di proses melalui tahapan metode Waterfall. 


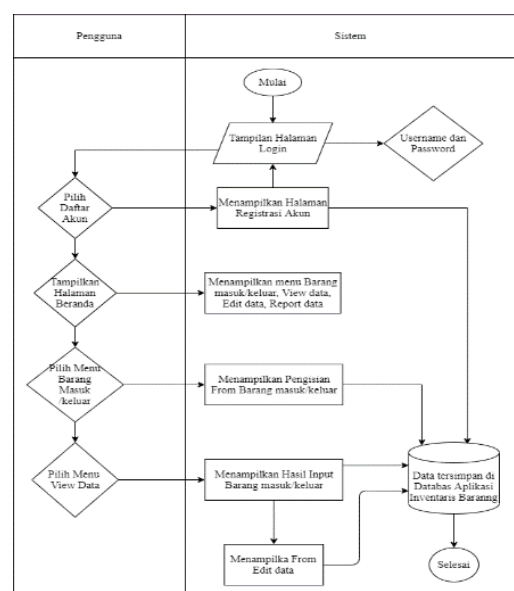

Gambar 3 Sistem yang di usulkan

\subsection{Tahapan sistem inventaris barang dengan metode Wterfall}

Tahapan ini merupakan dimana penilis akan memberikan penjelasan setiap tahapan yang terdiri dari 5 (lima) tahapan yaitu Requirement Specification (Analisa Kebutuhan), Design System (Desain Sistem), Coding and Testing (Pengkodean dan Pengujian), Integration and Testing (Penerapan dan Pengujian) dan Maintenance (Pemeliharaan) yang terangkum proses tahapan Waterfall.

\subsubsection{Analisa Sistem}

Dalam setiap tahapan-tahapan perlu adanya informasi mengenai sistem yang akan di buat agar segala keperluan dapat memberikan hasil yang baik nantinya. Menganalisa adalah tahapan awal dalam metode waterfall atau biasa disebut analisa kebutuhan yang dimana data yang diperlukan dalam beberapa tahapan seperti pengumpulan data dan pengelohan data melalui hasil wawancara pada SMP IT NURUL MUHAJIRIN pada bidang sarana prasarana.

\subsubsection{Desain Sistem}

Merancang sistem atau di awali dengan desain sistem merupakan tahapan selanjutnya setelah mendapatkan informasi dalam tahapan analisa sistem. Cukup banyak yang mencangkup dalam halnya di desain sistem ini dengan beberapa tahapan yang tidak bisa di perjelaskan satu persatu mengenai sistem yang dirancnag. Beberapa tahapan dalam desai sistem yang telah memeberikan gambaran untuk mengelola sistem yang akan dijalan kan seperti, use case diagram, activity diagram, class diagram, struktur database, dan user interface.

Berikut merupakan beberapa dari desain sistem untuk inventaris barang.

1. Ini merupakan gambaran awal masuk untuk melakukan login dan juga pendaftaran akun.

Sliahkan Login Terlebih Dahulu

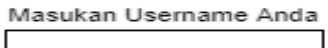

Masukan Username Anda

MASUK

Pengguna Baru ? Klik Daftar

Gambar 4. Menu login 
2. Setelah memasuki halaman awal. Selanjutnya merupakan gambaran halaman pada pendaftaran akun.

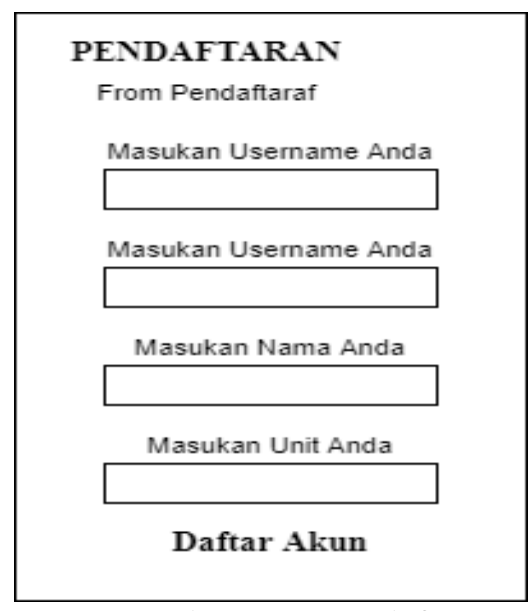

Gmabar 5. menu daftar

3. Selanjutnya adalah merupakan gambaran pada halaman beranda yang terdapat beberapa halamanan lain nya.

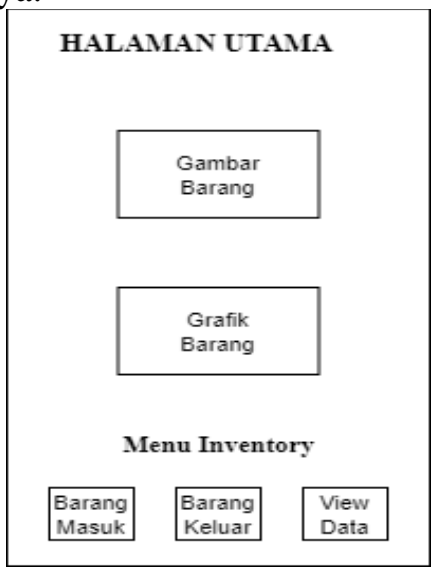

Gambar 6. menu beranda

4. Halaman selanjutnya adalah gambaran pada input barang masuk pada inventaris barang.

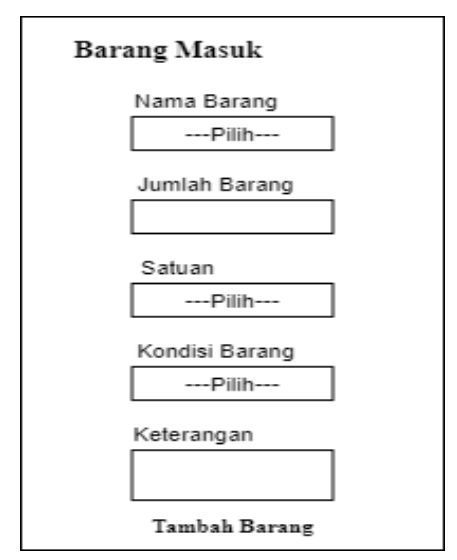

Gambar 7.barang masuk 
5. Pada gambaran input barang keluar hsail nya sama seperti gambaran barang masuk inventaris barang.

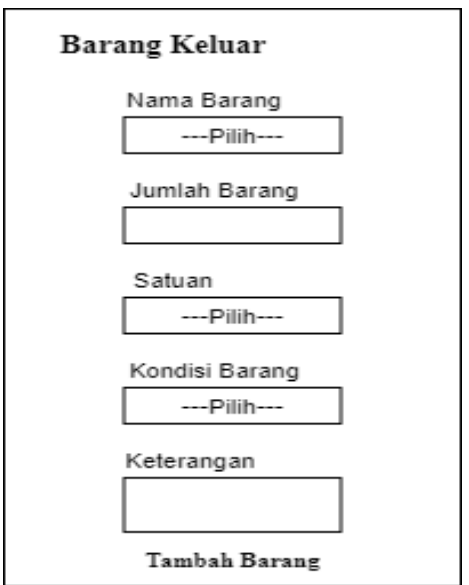

Gambar 8. barang keluar

6. Pada gambaran ini merupakan nantinya hasil dari input barang masuk dan barang keluar pada inventaris barang.

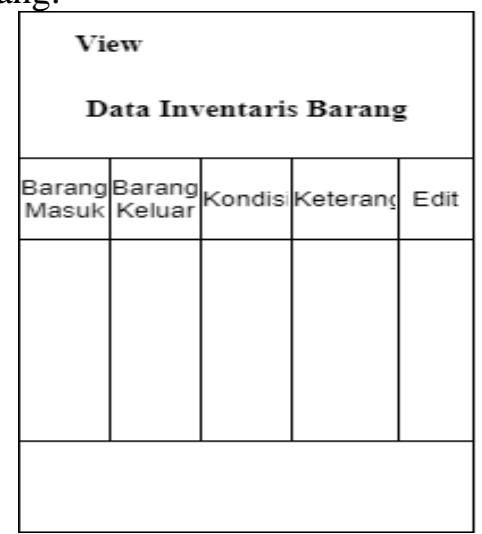

Gambar 9. View Data

7. Tahap akhir adalah gambaran dimana setelah selesai dan ingin melakukan keluar pada sistem inventaris barang.

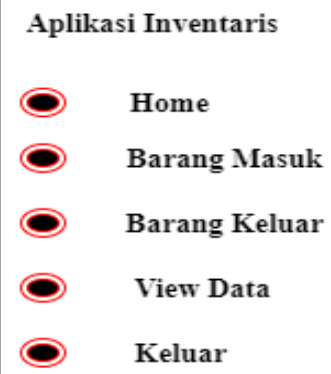

Gambar 10. menu keluar 


\subsubsection{Pengodean dan Pengujian}

Codinng and Testing (Pengkodean dan Pengujian) merupakan tahapan memulai proses pengkodeaan pada program aplikasi sistem inventaris berang berbasis aplikasi android. Setelah selesai melakukan pengkodean pada tahap ini juga akan melakukan pengujian setiapsetiap proses sisetem yang sudah selesai melalui tahapan pengkodean agar sistem tidak terjadi kesalahan ataupun eror saat dilakukan pengujian.

\subsubsection{Penerapan dan Pengujian}

Tahap ini merupakan dimana penulis melakukan pengujian pada tempat studi kasus atau bidang sarana prasarana di SMP IT NURUL MUAJIRIN untuk memastikan sistem inventaris agar tidak terjadi eror atau kesalahan pada sistem tersebut.

\subsubsection{Pemeliharaan}

Tahap akhir ini proses dimana akan melakukan pengecekan setiap sistem yang akan di perbarui atau update pada aplikasi inventaris barang.

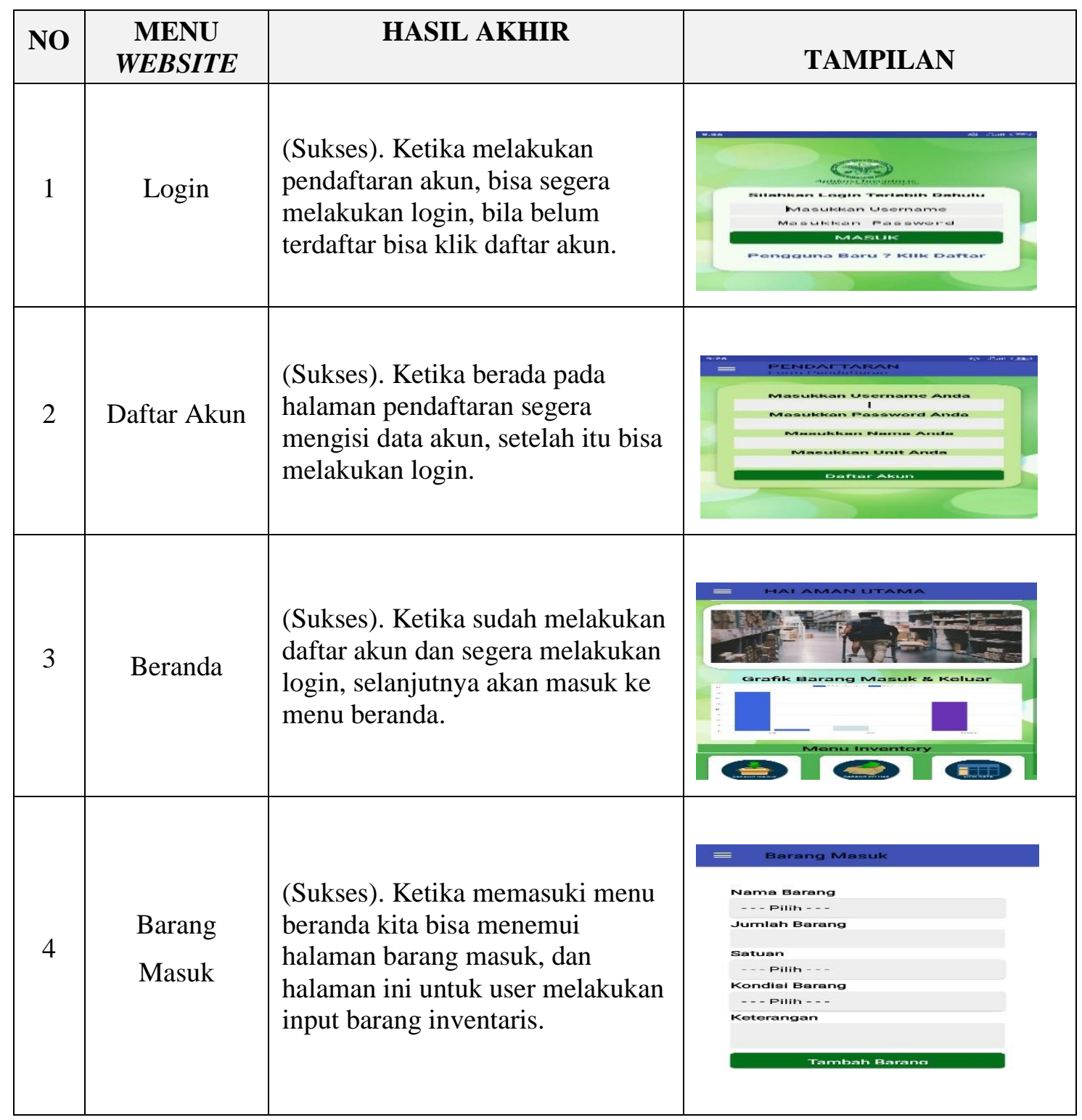




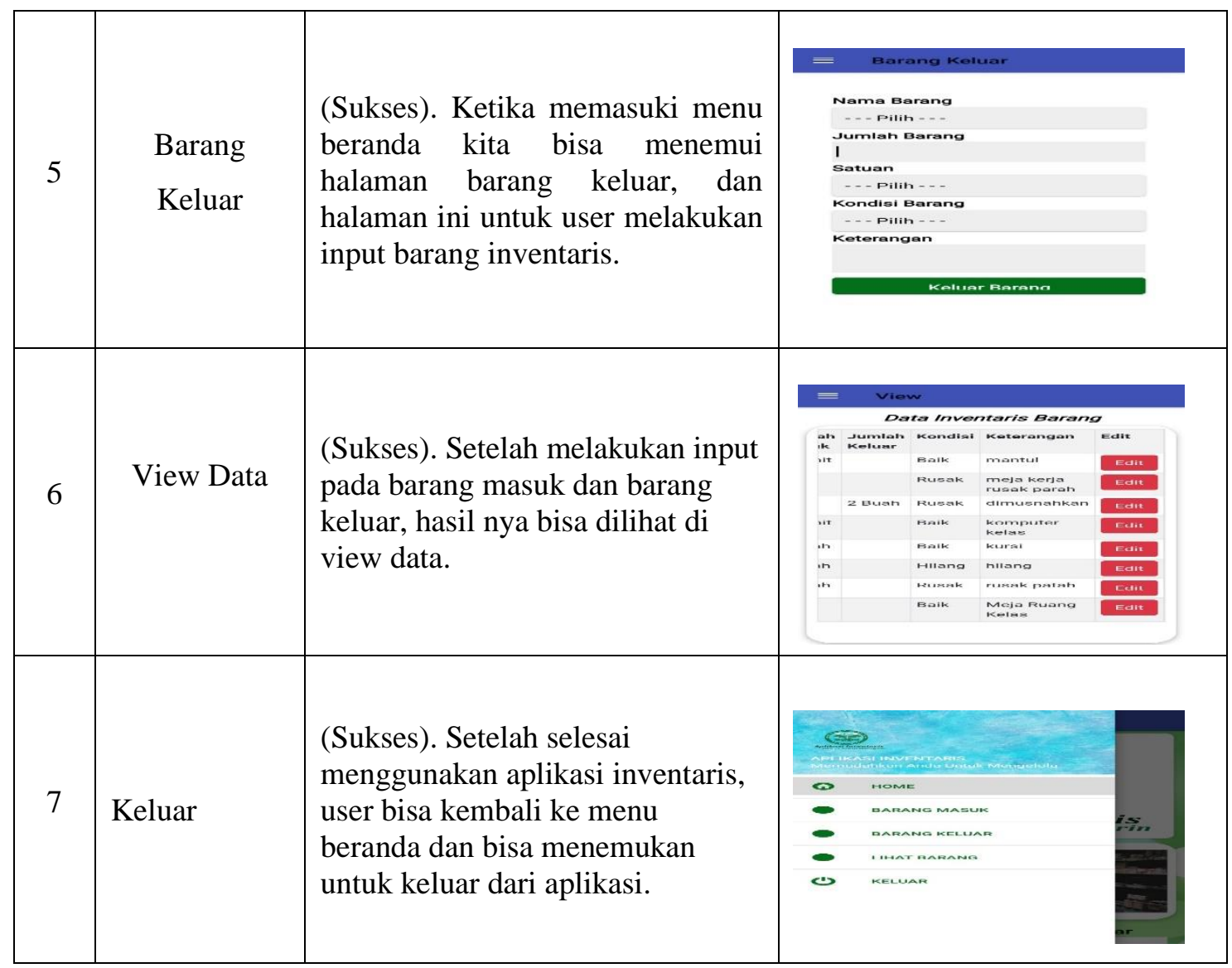

\section{KESIMPULAN}

Berdasarkan pengolahan dan analisa data serta pembahasan yang telah dilakukan, maka dapat disimpulkan sebagai berikut:

1. Secara umum penulis dapat memberikan kesimpulan bahwa setiap perubahan itu ada bila kita ingin memulainya. Adanya kenuntungan dalam mempermudah setiap pekerjaan dalam memberikan sistem aplikasi inventaris berbasis android

2. Pengelolaan terhadap data-data inventaris barang di bidang sarana prasrana di SMP IT NURUL MUHAJIRIN sangat berbeda pada saat sebelum nya, karena sesudah adanya sistem inventaris barang berbasis aplikasi android pekerjaan menjadi mudah dalam proses mendata setiap barang yang di input kedalan sistem .

\section{SARAN}

Berikut ini merupakan beberapa saran penulis guna dijadikan pertimbangan dalam pembuatan sistem informasi inventaris berbasis android pada SMP IT NURUL MUHAJIRIN.

1. Harus memahami sebelum melakukan proses pada aplikasi inventaris barang.

2. Memberikan kemudahan pada pekerjaan harus lebih teliti untuk melakukan input pada data inventaris barang.

3. Bekerja lah dengan ikhlas agar hati selalu mersa nyaman pada pekerjaan sendiri. 


\section{DAFTAR PUSTAKA}

[1] Angairini. 2017. Perancangan Sistem Informasi Manajemen Data Korban Bencana Berbasis Mobile Android).

[2] Erri Wahyu Puspitarini, Dian Wahyu Putra, A. Prasita Nugroho. (2016). Game Edukasi Berbasis Android Sebagai Media Pembelajaran Untuk Anak Usia Dini. 1(1). 46-58

[3] Ezra R, Yulhendra D (2020). Perancangan Program Aplikasi Geometri Peledakan Tambang Terbuka Berbasis Mobile Menggunakan Bahasa Pemrograman Android Studio. 5(2). 159173

[4] Haris Budiman (2017). Peran Teknologi Informasi Dan Komunikasi Dalam Pendidikan. 8 (1), 31-43

[5] Huda, Nurul (2020). Implementasi Sistem Informasi Inventaris Barang pada PT.PLN (Persero) Palembang. 9(1). 13

[6] Julius, Fernaldy Putra, Alfa Satya Tjahyadi, Hendra (2019). Desain dan implementasi path following drone.

[7] Muliadi, dkk (Astuti, 2016). Perancangan Sistem Informasi Pemesanan Kamar Hotel Berbasis Website (Web) Menggunakan Data Flow Diagram (Dfd). 7(2). 111-122.

[8] Nasution A, Efendi B, Siregar, I, K (2019). Pelatihan membuat aplikasi android dengan android studio pada SMP NEGERI 1 TINGGI RAJA pendahuluan SMPN 1 Tinggi Raja sebagai salah satu Lembaga pendidikan Formal yang menyelenggarakan jenjang pendidikan menengah pertama (SMP). Salah satu yang menjadi t. 2(1) 53-58

[9] Nofyat Dkk (2018). Sistem Informasi Pengaduan Pelangganan Air Berbasis Website Pada PDAM KOTA TERNATE. 